\title{
MicroRNA expression patterns in canine mammary cancer show significant differences between metastatic and non- metastatic tumours
}

Malgorzata Bulkowska ${ }^{1+}$, Agata Rybicka $^{1 \dagger}$, Kerem Mert Senses$^{2}$, Katarzyna Ulewicz ${ }^{1}, K^{\prime}$ atarzyna Witt ${ }^{1}$, Joanna Szymanska', Bartlomiej Taciak', Robert Klopfleisch³, Eva Hellmén ${ }^{4}$, Izabella Dolka ${ }^{5}$, Ali O. Gure², Joanna Mucha ${ }^{1}$, Mariusz Mikow ${ }^{6}$, Slawomir Gizinski ${ }^{7}$ and Magdalena Krol ${ }^{1 *}$

\begin{abstract}
Background: MicroRNAs may act as oncogenes or tumour suppressor genes, which make these small molecules potential diagnostic/prognostic factors and targets for anticancer therapies. Several common oncogenic microRNAs have been found for canine mammary cancer and human breast cancer. On account of this, large-scale profiling of microRNA expression in canine mammary cancer seems to be important for both dogs and humans.

Methods: Expression profiles of 317 microRNAs in 146 canine mammary tumours of different histological type, malignancy grade and clinical history (presence/absence of metastases) and in 25 control samples were evaluated. The profiling was performed using microarrays. Significance Analysis of Microarrays test was applied in the analysis of microarray data (both unsupervised and supervised data analyses were performed). Validation of the obtained results was performed using real-time GPCR. Subsequently, predicted targets for the microRNAs were searched for in miRBase.
\end{abstract}

Results: Results of the unsupervised analysis indicate that the primary factor separating the samples is the metastasis status. Predicted targets for microRNAs differentially expressed in the metastatic vs. non-metastatic group are mostly engaged in cell cycle regulation, cell differentiation and DNA-damage repair. On the other hand, the supervised analysis reveals clusters of differentially expressed microRNAs unique for the tumour type, malignancy grade and metastasis factor.

Conclusions: The most significant difference in microRNA expression was observed between the metastatic and nonmetastatic group, which suggests a more important role of microRNAs in the metastasis process than in the malignant transformation. Moreover, the differentially expressed microRNAs constitute potential metastasis markers. However, validation of cfa-miR-144, cfa-miR-32 and cfa-miR-374a levels in blood samples did not follow changes observed in the non-metastatic and metastatic tumours.

Keywords: microRNA, Canine mammary cancer, Human breast cancer

\footnotetext{
*Correspondence: magdalena_krol@sggw.pl

${ }^{\dagger}$ Equal contributors

'Department of Physiological Sciences, Faculty of Veterinary Medicine,

Warsaw University of Life Sciences, Nowoursynowska 159, 02-776 Warsaw,

Poland

Full list of author information is available at the end of the article
} 


\section{Background}

Mammary tumours occur spontaneously in dog and human populations [1]. Epidemiology of this disease is similar in both species, partly due to the dog being a companion animal, i.e. living in similar environmental conditions to humans. Canine and human mammary tumours are hormone-dependent and usually originate from epithelial tissue [2]. The most common histological type of malignant mammary tumours in dogs is complex carcinoma [3] and that of human breast cancer is invasive ductal carcinoma [4]. Canine mammary carcinoma frequently invades lymph nodes and metastasises to the lungs $[5,6]$, but rarely to the bones [6, 7]. Human breast cancer often spread to lymph nodes, lungs, bones and to the liver [8]. Many similar oncogenes were found for human breast cancer and canine mammary carcinoma, for instance oncogenic microRNAs [9]. Moreover, many changes in pathways related to mammary cancer (including KRAS, PTEN, PI3K/AKT, WNT-beta catenin and MAPK cascade) are common for both species [10]. All these molecular similarities made canine mammary cancer a good genetic model for human breast cancer [11].

Some microRNAs are up-regulated and some are downregulated in cancer, which suggests that microRNAs may act as oncogenes or tumour suppressor genes [12]. Many microRNAs are located in fragile sites (FRAs) - preferential sites of alterations (e.g. amplification or deletion) in a genome. Hence, amplification of chromosomal regions containing oncogenic microRNAs and/or deletion of sites including suppressor microRNAs may lead to cancer development [13]. When showing the connection between microRNA expression and cancer it is also very important to establish microRNA's functional role. For example, p53 activates the expression of miR-34a, which then promotes apoptosis [14]. MiR-27a inhibits the expression of the Sp repressor ZBTB10/RINZF [15], leading to the overexpression of Sp factors and, as a consequence, to the increase of Sp-dependent antiapoptotic and angiogenic molecules' number, e.g. survivin and vascular endothelial growth factor (VEGF), responsible for cancer development [16]. MiR-10b suppresses the homeobox D10 (HOXD10). Expression of HOXD10 releases the pro-metastatic gene RHOC and results in tumour invasion and metastasis [17]. In general, all these findings suggest that microRNAs may serve as diagnostic and prognostic factors.

Expression profiles of a few microRNAs have been investigated in canine mammary cancer. Von Deetzen et al. compared the expression profiles of 16 microRNAs (miR-136, miR-143, let-7f, miR-29b, miR-145, miR-9, miR10b, miR-203, miR-125b, miR-15a, miR-16, miR-21, miR101, miR-210, miR-194 and miR-125a) in three types of canine mammary tumours (adenoma, non-metastasising carcinoma, metastasising carcinoma), lymph node metastases and in a normal mammary gland. One of their results was the higher expression level of miR-210 in all neoplastic tissues in comparison to the normal gland. They also found that miR-29b, miR-101, miR-143, miR145 and miR-125a are down-regulated in metastatic sites when compared to the primary tumours. Further, they did not find any significant difference in miR-9, miR-10b, miR-15a, miR-16, miR-125b, miR-136 and let-7f expression levels among the examined groups [18].

Our study is the first to identify the expression profiles of 317 microRNAs in canine mammary tumours of different histological type, malignancy grade and clinical history (presence or absence of metastases) and in a control group (normal mammary gland samples). This work was performed using microarrays - a novel largescale profiling method.

\section{Methods}

\section{Tumour sample collection}

Tumour samples were collected during mastectomy performed according to standard veterinary procedures. One half of every tumour was immersed in $10 \%$ neutral buffered formalin and stored at room temperature. The other was immersed in RNAlater ${ }^{\circ}$ Stabilization Solution (Ambion, USA) and stored at $-80^{\circ} \mathrm{C}$. The total number of obtained samples amounts to 171 (39 samples were received from veterinary clinics in Warsaw (Poland), 104 samples - from the Freie Universitaet Berlin (Berlin, Germany) and 28 samples - from the Swedish University of Agricultural Sciences (Uppsala, Sweden)). The samples from Germany and Sweden were shipped to Poland in RNAlater ${ }^{\bullet}$ Stabilization Solution on dry ice. Radiography was used for the diagnosis of metastases for the cases in Poland. The samples from Sweden were obtained from dogs that died or were euthanized due to their mammary carcinoma. This was confirmed by a post-mortem examination or x-ray of the lungs and the latter was based on the information from the clinician or from the owner [19].

\section{Tumour classification and immunohistochemistry}

Histological classification of the tumours was performed according to the World Health Organization (WHO) Histological Classification of Mammary Tumors in the Dog and Cat [20]. Grades of malignancy were allocated in accordance with the Nottingham method for human breast tumours, which is based on the assessment of three morphological features: mitotic counts, nuclear pleomorphism and tubule formation [21]. Tumoural characteristics of the samples No. 26-144 were assessed by immunohistochemical examination of cytokeratin, vimentin, smooth muscle actin, s100 protein and p63 protein expression.

For immunohistochemical analysis, tumour samples were embedded in paraffin. 3- $\mu$ m-thick sections of the tumours were cut, fixed on slides and dried overnight at $37^{\circ} \mathrm{C}$. After 
drying, slides were dewaxed in xylene, rehydrated in ethanol, boiled in $0.02 \mathrm{M}$ citrate buffer ( $\mathrm{pH}$ 6.0), washed in $\mathrm{H}_{2} \mathrm{O}_{2}$, washed with distilled water, washed in phosphate buffered saline (PBS) and incubated in 1-2\% bovine serum albumin. Afterwards, sections were incubated overnight at $4^{\circ} \mathrm{C}$ in primary antibodies diluted in $1-2 \%$ bovine serum albumin. The following primary antibodies were used: Monoclonal Mouse Anti-Human Cytokeratin, Clone MNF116, 1:50 (Dako, Agilent Technologies, USA); Monoclonal Mouse Anti-Vimentin, Clone Vim 3B4, 1:100 (Dako); Monoclonal Mouse Anti-Human Actin (Muscle), Clone HHF35, 1:50 (Dako); Polyclonal Rabbit Anti-S100, 1:400 (Dako) and Monoclonal Mouse Anti-Human p63 Protein, 1:50 (Dako). After incubation in primary antibodies, slides were washed in PBS. Subsequently, staining was performed using EnVision $^{\mathrm{Tm}}+$ System-HRP (DAB) Kit (Dako). Tumour sections were incubated in Labelled Polymer-HRP (polymer conjugated with horseradish peroxidase enzyme) and in 3,3`-diaminobenzidine (DAB) chromogen (diluted according to the manufacturer's protocol). After chromogen reaction, slides were washed under cold running water, stained with haematoxylin and eosin, washed again under cold running water and dehydrated in alcohol and in xylene. Coverslips on slides were fixed using Mounting Medium (Dako). Slides with coverslips were dried overnight at $37^{\circ} \mathrm{C}$. Antigen spots were counted by a computer-assisted image analyser (Olympus Microimage ${ }^{\text {тм }}$ Image Analysis, software version 4.0 for Windows, Japan).

\section{RNA isolation from tumour samples}

RNA was isolated from tumour pieces with a diameter of $1 \mathrm{~cm}$. Each piece was washed with RNase Away Reagent (Ambion) and disrupted in Tissue Lyser LT (QIAGEN, Germany) at $50 \mathrm{~Hz}$ for $30 \mathrm{~min}$. After disruption, total RNA was isolated from samples using miRNeasy Mini Kit (QIAGEN) according to the manufacturer's protocol. Isolated RNA was stored at $-80^{\circ} \mathrm{C}$. RNA quantity and contamination with proteins and organic compounds were examined using NanoDrop 2000 (NanoDrop, USA). RNA integrity was assessed using Agilent 2100 Bioanalyzer (Agilent Technologies, USA).

\section{MicroRNA microarray profiling}

Samples (750 ng of total RNA) were labelled with fluorescent labels (examined samples with $\mathrm{Hy}^{\text {тм }}$ label - green fluorescence, reference samples with $\mathrm{Hy}^{\mathrm{TM}}$ label - red fluorescence) using miRCURY LNA ${ }^{\mathrm{TM}}$ microRNA Hi-Power Labeling Kit, $\mathrm{Hy}^{{ }^{\mathrm{Tx}}} / \mathrm{Hy}^{\mathrm{rs}}$ (Exiqon, Denmark) according to the manufacturer's protocol. The $\mathrm{Hy} 3^{\mathrm{rm}}$-labelled examined samples and $\mathrm{Hy} 5^{\mathrm{ma}}$-labelled reference samples were mixed pair-wise and hybridized on miRCURY LNA ${ }^{\mathrm{Tm}}$ microRNA Array 7th generation - hsa, mmu \& rno (Exiqon) using Tecan HS4800TM Hybridization Station (Tecan, Austria). After hybridization, microarray slides were scanned and stored in an ozone free environment (ozone level below
$2.0 \mathrm{ppb})$. Scanning was carried out using Agilent G2565BA Microarray Scanner (Agilent Technologies). Image analysis was performed using ImaGene 9.0 software (BioDiscovery, USA). Quantified signals were normalized using quantile normalization method.

Both unsupervised and supervised analyses of data were performed. Unsupervised analysis was carried out without dividing samples into groups and it includes Principal Component Analysis (PCA) and unsupervised hierarchical clustering (two-way hierarchical clustering). For supervised analysis, samples were divided into groups according to three factors: tumour type, malignancy grade, and metastasis. Unsupervised and supervised analyses of data were performed using BRBArrayTools, Version 4.3.2 (developed by Dr. Richard Simon and BRB-Array Tools Development Team). For the unsupervised analysis, the variances of microRNAs were calculated using Excel's VAR.S function. For the supervised analysis, Significance Analysis of Microarrays (SAM) test, which sets estimate of False Discovery Rate for multiple testing, was applied. Results of the analyses are shown on heat maps and 3D-PCA plots. Heat maps were drawn using BRB-ArrayTools, 3D-plots - using Python programming version 3.4 [22] with the Matplotlib version 1.4.3 data visualization package [23]. To make heat maps, the normalized expression values of microRNAs were standardized by the Excel's STANDARDIZE function, then on the heat map an expression level below the mean was represented by green colour and an expression level above the mean was represented by red colour.

\section{Validation of microarray results}

For validation of microarray results were selected microRNAs showing more than 2-fold up- or down-regulation (LogFoldChange above +1.0 or below -1.0 ), statistically significant regulation (adjusted $p$-values $<0.05$ ) and average array signal intensity of the probes well above the background (in the range 7.5-14.5). The real-time quantitative PCR (RT-qPCR) method was applied for the validation. cDNA synthesis was carried out using Universal cDNA Synthesis Kit (Exiqon) according to the manufacturer's protocol in Eppendorf MasterCycler Personal thermal cycler (Eppendorf, Germany). RT-qPCR was performed using LNA $^{\mathrm{TM}}$ PCR primer sets (Exiqon) and ExiLENT SYBR ${ }^{\circledR}$ Green master mix (Exiqon) according to the manufacturer's protocol in Stratagene Mx3005P qPCR System (Agilent Technologies). Target sequences for the primer sets are shown in Additional file 1. The results of RT-qPCR were analysed using GenEx 6 software (Exiqon).

\section{Validation of selected targets for microRNAs deregulated in metastatic canine mammary cancer}

The following 17 genes were selected for validation of predicted targets for microRNAs deregulated in metastatic 
canine mammary cancer: CDC6, CCNE1, MYBL2, PDCD10, ERBB2IP, SON, STK4, CDC27, PRC1, CDC37, TTK, SKIL, BUB3, SPIN1, EEF2, ACTB and HPRT. The RT-qPCR method was applied for the validation. cDNA synthesis was performed using High Capacity RNA-tocDNA Kit (Life Technologies, USA) according to the manufacturer's protocol in MasterCycler ${ }^{\oplus}$ pro PCR System (Eppendorf). RT-qPCR was carried out using Oligo.pl primer sets (Oligo, Poland) and $\mathrm{SYBR}^{\circ}$ Select Master Mix (Life Technologies) according to the manufacturer's protocol in Stratagene Mx3005P qPCR System (Agilent Technologies). The primers' sequences are shown in Additional file 2. The results of RT-qPCR were analysed using GraphPad Prism 6 (GraphPad Software, USA).

\section{Blood samples}

Whole blood samples were obtained from 50 female dogs diagnosed with canine mammary tumours. All these samples were collected during cephalic vein catheterization prior to mastectomy in the Department of Small Animal Diseases with Clinic (Faculty of Veterinary Medicine, Warsaw University of Life Sciences) and in two private veterinary clinics in Warsaw except a bitch that was not qualified for surgery due to lung metastasis. From this patient, blood was taken from the cephalic vein by catheterization before euthanasia. In brief, 38 dogs with non-metastatic tumours (10 benign and 28 malignant tumours in various stages) and 12 dogs with tumour recurrence or metastasis were qualified for this study. Detailed characteristics of all the samples are included in Additional file 3.

For a control group, 12 blood samples were collected from healthy bitches during routine veterinary examination before ovariohysterectomy in two private veterinary clinics in Warsaw. Patients with possible diseases and pathological stages, which might influence the study and its results, were excluded.

All dogs underwent standard clinical examination before the procedure, including: the patient's history, complete physical examination, documentation of tumour characteristics, haematological examination, serum biochemistry profile and three thoracic radiographic projections - right, left lateral and dorsoventral. Four millilitres of blood were collected into $6 \mathrm{ml} \mathrm{K} \mathrm{K}_{2}$ EDTA plastic tubes (BD Vacutainer) and centrifuged on the same day at 4000 RPM for $15 \mathrm{~min}$ at $4{ }^{\circ} \mathrm{C}$. Plasma was next carefully aspirated and transferred into a new tube and centrifuged again under the same conditions. Finally, the supernatant was transferred into a new tube and stored at $-80^{\circ} \mathrm{C}$ until RNA isolation.

\section{RNA isolation from plasma samples}

MicroRNA was extracted using QIAamp Circulating Acid Kit (QIAGEN) according to the manufacturer's protocol for $1 \mathrm{ml}$ of plasma. In the last step of the procedure, microRNA was suspended in $40 \mu \mathrm{l}$ of elution buffer AVE. The quantity of microRNA was measured using NanoDrop Spectrophotometer (NanoDrop Technologies, USA) whereas RNA quality and integrity were assessed using BioAnalyzer (Agilent, USA). Only samples with a RIN $>8$ were taken to the further study.

\section{CDNA synthesis and quantitative real time PCR for plasma microRNAs}

Four commercially available microRNA LNA PCR primer sets (cfa-miR-144, cfa-miR-32, cfa-miR-374a and hsa-miR1246 (Exiqon)) were selected as metastasis-specific and used to evaluate microRNA levels in each plasma sample. Additionally, four microRNAs were chosen as controls (according to Blondal et al.) for all the samples to investigate possible haemolysis and erythrocyte contamination, which might alter microRNA levels in samples [24]. Two microRNAs affected (hsa-miR-425-5p and hsa-miR-486$3 p)$ and two non-affected by haemolysis (hsa-miR-744-5p and hsa-miR-340-5p) were selected [25]. However, in the final calculations, the most sensitive and detectable microRNAs in all the samples were used (i.e. hsa-miR-486-3p and hsa-miR744). Target sequences for the primer sets are shown in Additional file 4.

The formula proposed by Blondal et al. identifies haemolysis based on the value obtained by substracting dCT hsamiR-486-3p from dCT hsa-miR-744. Samples with a ddCT $>5$ are considered as haemolysed and samples with a ddCT between 7 and 8 are considered as strongly haemolysed [24].

cDNA synthesis was performed using Universal cDNA Synthesis Kit (Exiqon) according to the manufacturer's protocol in Eppendorf Master Cycler Personal thermal cycler (Eppendorf, Germany). Samples were further frozen and stored at $-20{ }^{\circ} \mathrm{C}$. The synthetized cDNA was diluted 1:40 and used within $24 \mathrm{~h}$ for qRT-PCR carried out using ExiLENT SYBR ${ }^{\circ}$ Green master mix (Exiqon). $10 \mu \mathrm{l}$ of a reaction mixture consists of $5 \mu \mathrm{l}$ of PCR Master Mix, $1 \mu \mathrm{l}$ of PCR primer mix and $4 \mu \mathrm{l}$ of diluted cDNA template. Each reaction was run in triplicate on a 96-well plate using Stratagene Mx3005P qPCR System (Agilent Technologies). Results of qRT-PCR were calculated using the comparative Ct method [26] and statistically analysed by Prism version 6.00 software (GraphPad Software, USA). An unpaired, non-parametric MannWhitney test was applied to compare the difference of microRNAs expression between the non-metastatic and metastatic group. Statistical significance was defined as $p$-value $<0.05$. Due to the magnitude and range of observed results, the data was log-transformed for analysis.

\section{Results}

Sample characteristics

A total of 171 samples were included in this study, 146 of which were canine mammary tumours (30 benign 
tumours and 116 malignant tumours) and 25 were normal mammary gland samples. The group of malignant tumours consisted of 115 carcinoma samples and one carcinosarcoma case. The malignant tumours were of different histological subtypes (histological classification of the samples is included in Table 1), grades of malignancy (grade I - 27 samples, grade II - 29 samples, grade III - 27 samples, unknown - 33 samples) and clinical histories (presence of metastases - 58 samples, absence of metastases - 49 samples, unknown - 9 samples). Detailed characteristics of all the samples included in the study are shown in Additional file 5.

\section{MicroRNA microarray analysis}

The technical data quality assessment showed that the sample labelling with $\mathrm{Hy}^{\mathrm{ma}}$ and $\mathrm{Hy}^{\mathrm{mi}}$ fluorescent labels was successful as all capture probes for the control spike-in oligonucleotides produced signals in the expected range. Subsequently, a total of 317 microRNAs were used for threshold filtering and 122 probes were discarded by the filtering procedure. The obtained number of present calls for the samples was within the expected range.

Both unsupervised and supervised analyses of data were performed. Unsupervised analysis includes Principal Component Analysis and unsupervised hierarchical clustering (two-way hierarchical clustering). Principal Component Analysis was conducted to reduce the dimensions of large data sets and to explore the naturally arising sample classes based on the expression profile. By including the top 50 microRNAs with the largest variation across all the samples, we obtained an overview of how the samples clustered based on this variance. This led to the separation of the samples in different regions of a PCA plot corresponding to their biology. The result of PCA is presented as a 3D-PCA plot (Fig. 1). The 3D-PCA plot reveals the distinct sample clusters for metastatic tumours, non-metastatic tumours and the control group. Unsupervised hierarchical clustering (two-way hierarchical clustering of microRNAs and samples) was performed using the complete-linkage method together with the Euclidean distance measure. The result of this analysis is shown in Fig. 2. In general, the unsupervised analysis shows that the primary factor separating the samples is the metastatic status.

For supervised analysis, samples were divided into groups according to three factors: tumour type, malignancy grade and metastatic status (the histological subtype was not used as a factor for any analysis because of a large number of groups with widely varying sizes). Significance Analysis of Microarrays test for each of the three factors was performed. For the tumour type factor, a subset of 123 microRNAs was identified out of the total of 195 analysed microRNAs that are significantly
Table 1 Histological classification of the tumour samples (summary)

\begin{tabular}{|c|c|c|c|}
\hline Control/Tumour type & Histological type & No. & $\Sigma$ \\
\hline Control & & 25 & 25 \\
\hline \multirow[t]{10}{*}{ Benign tumour } & Simple adenoma & 3 & 30 \\
\hline & Complex adenoma & 16 & \\
\hline & Atypical adenoma & 1 & \\
\hline & Atypical simple adenoma & 1 & \\
\hline & Atypical complex adenoma & 1 & \\
\hline & Basaloid adenoma & 1 & \\
\hline & Atypical papilloma & 3 & \\
\hline & Benign mesenchymal tumour & 2 & \\
\hline & Benign mixed tumour & 1 & \\
\hline & $\begin{array}{l}\text { Simple adenoma + Complex } \\
\text { adenoma }\end{array}$ & 1 & \\
\hline \multirow[t]{21}{*}{ Malignant tumour } & Solid carcinoma & 22 & 113 \\
\hline & Simple carcinoma & 1 & \\
\hline & Complex carcinoma & 16 & \\
\hline & Tubulopapillary carcinoma & 30 & \\
\hline & Noninfiltrating carcinoma & 3 & \\
\hline & Comedocarcinoma & 16 & \\
\hline & Squamous cell carcinoma & 3 & \\
\hline & Basaloid carcinoma & 1 & \\
\hline & Anaplastic carcinoma & 3 & \\
\hline & Lipid-rich carcinoma & 2 & \\
\hline & Mucinous carcinoma & 1 & \\
\hline & Scirrhous carcinoma & 3 & \\
\hline & Carcinoma & 1 & \\
\hline & Special type of carcinoma & 1 & \\
\hline & Carcinosarcoma & 1 & \\
\hline & $\begin{array}{l}\text { Tubulopapillary carcinoma/ } \\
\text { Noninfiltrating carcinoma }\end{array}$ & 1 & \\
\hline & $\begin{array}{l}\text { Solid carcinoma / Lipid-rich } \\
\text { carcinoma }\end{array}$ & 1 & \\
\hline & $\begin{array}{l}\text { Tubulopapillary carcinoma + } \\
\text { Solid carcinoma }\end{array}$ & 2 & \\
\hline & $\begin{array}{l}\text { Mucinous carcinoma }+ \\
\text { Tubulopapillary carcinoma }\end{array}$ & 1 & \\
\hline & $\begin{array}{l}\text { Tubulopapillary carcinoma }+ \\
\text { Bi-phasic carcinoma }\end{array}$ & 1 & \\
\hline & Unknown & 3 & \\
\hline \multirow[t]{2}{*}{$\begin{array}{l}\text { Malignant tumour } \\
+ \text { benign tumour }\end{array}$} & $\begin{array}{l}\text { Tubulopapillary carcinoma }+ \\
\text { Complex adenoma }\end{array}$ & 1 & 2 \\
\hline & $\begin{array}{l}\text { Tubulopapillary carcinoma }+ \\
\text { Noninfiltrating carcinoma }+ \\
\text { Benign mixed tumour }\end{array}$ & 1 & \\
\hline $\begin{array}{l}\text { Malignant tumour } \\
+ \text { hyperplasia }\end{array}$ & $\begin{array}{l}\text { Complex carcinoma }+ \\
\text { Mammary ductal ectasia }\end{array}$ & 1 & 1 \\
\hline
\end{tabular}



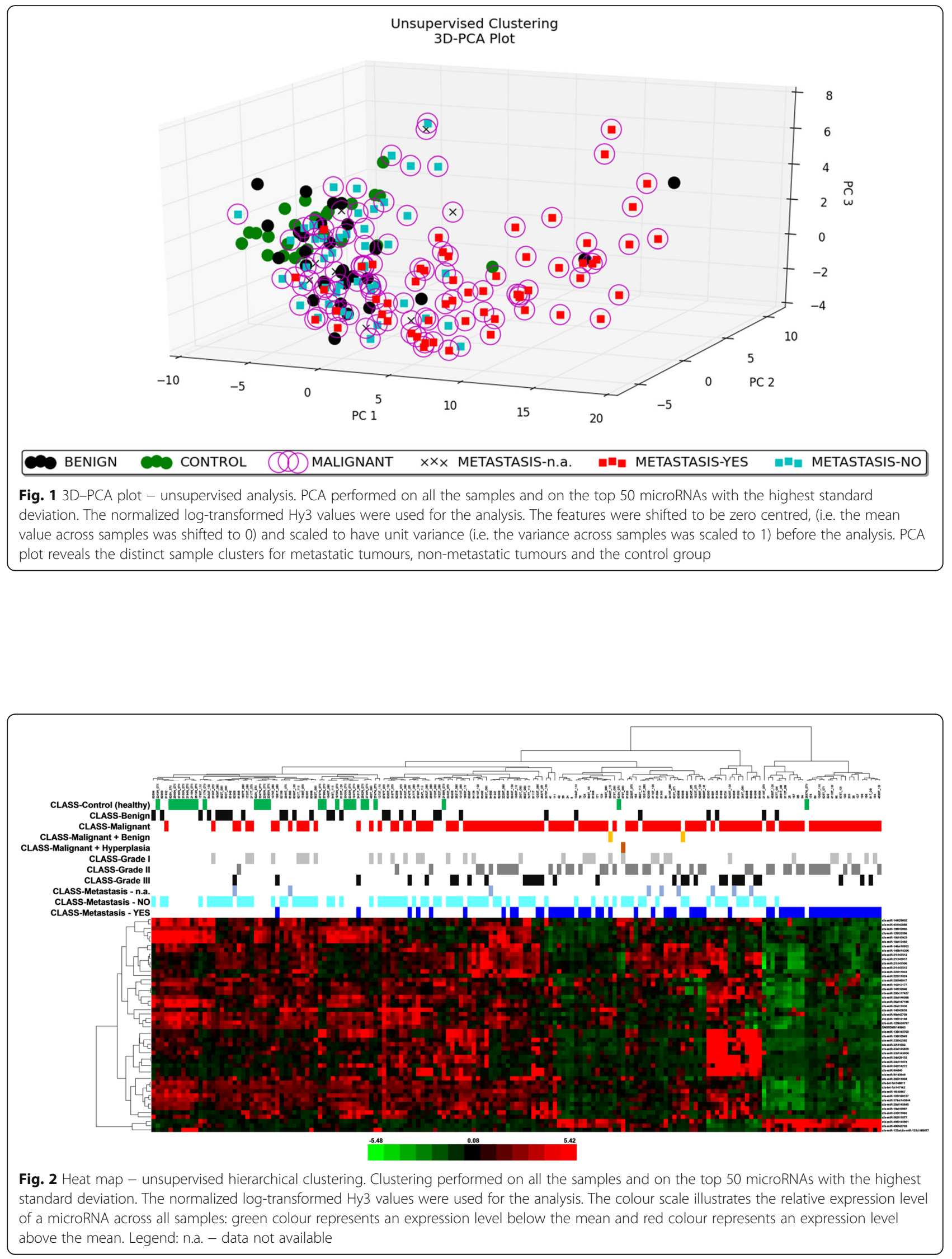
differentially expressed in different groups (the controls, benign tumours and malignant tumours). Of these 123 microRNAs, 84 miRNAs were down-regulated in the malignant tumour group in comparison with the control group, seven miRNAs were up-regulated in the malignant group compared to the controls, 20 miRNAs were down-regulated in the malignant tumours when compared to the benign tumour group, three miRNAs were up-regulated in the malignant group in comparison with the benign group, eight miRNAs were up-regulated in the benign tumours compared to the controls and one miRNAs was down-regulated in the benign tumour group when compared to the controls. The results of this analysis are shown in Additional file 6. One of the samples used in this analysis was marked as 'malignant + hyperplasia, as it was classified as a mixed histological type. The microRNA profile of this sample was mostly similar to the malignant group, because the specimen included probably the malignant part of a tumour as the main component. For the grade of malignancy, 131 differentially expressed microRNAs were identified (Additional file 7) in the following groups: grade I, grade II and grade III (including 13 miRNAs down-regulated in the grade II group when compared to the grade I group, 95 miRNAs up-regulated in the grade III group in comparison with the grade II group, one miRNAs down-regulated in the grade III group when compared to the grade I group, ten miRNAs down-regulated in the grade III group in comparison with the grade II group, ten miRNAs up-regulated in the grade III group when compared to the grade I group and two miRNAs upregulated in the grade II group compared to the grade I group); and for the metastasis factor - 124 miRNAs (Additional file 8) in the metastatic and non-metastatic group (including 98 miRNAs down-regulated and 26 miRNAs up-regulated in the metastatic group in comparison with the non-metastatic group). In general, the most distinct differences in microRNA profiles are between the control and malignant group for the tumour type factor (microRNAs mostly down-regulated in the malignant group) and between the metastatic and nonmetastatic group for the metastasis factor (microRNAs mostly down-regulated in the metastatic group). To enable quick visual identification of microRNAs displaying large-magnitude changes that are also statistically significant, the expression data were plotted in heat maps (tumour type - Fig. 3, grade of malignancy - Fig. 4, metastasis - Fig. 5). For these microRNAs, PCA plots were also performed (tumour type - Fig. 6, grade of malignancy - Fig. 7, metastasis - Fig. 8).

\section{Validation of microarray results}

The following ten microRNAs were selected for validation of microarray results: cfa-let-7c, cfa-miR-10b, cfa-
miR-26a, cfa-miR-26b, cfa-miR-29c, cfa-miR-30a, cfamiR-30b, cfa-miR-30c, cfa-miR-148a and cfa-miR-299. Average array signal intensity of the probes, $p$-values and fold changes for these microRNAs can be found in Additional file 8 . The validation was performed on 47 samples including five controls, five benign tumours, ten malignant non-metastatic tumours and 27 malignant metastatic tumours. The validation results are shown in Table 2. All the validated microRNAs are significantly differentially expressed among the examined groups. However, the distinction among the expression levels of these microRNAs in the groups is not as marked as in the microarray analysis.

\section{Validation of selected targets for microRNAs deregulated in metastatic canine mammary cancer}

For validation of predicted targets for microRNAs deregulated in metastatic canine mammary cancer were selected 14 genes, which expression differ in the metastatic and non-metastatic group (CDC6, CCNE1, MYBL2, PDCD10, ERBB2IP, SON, STK4, CDC27, PRC1, CDC37, TTK, SKIL, BUB3 and SPIN1). Three housekeeping genes (EEF2, ACTB, and HPRT) were used as controls. The function of selected target genes and the list of microRNAs, which regulate their expression, are included in Additional file 9. The validation was performed on 20 samples (ten malignant non-metastatic tumours and ten malignant metastatic tumours). The validation results are shown in Fig. 9 and in Table 3. Klopfleisch et al. found the higher expression of CDC6, CCNE1, MYBL2, PDCD10, ERBB2IP, SON, STK4, CDC27, PRC1, CDC37, TTK, SKIL, BUB3 and SPIN1 in metastatic canine mammary cancer in comparison with non-metastatic canine mammary cancer [27]. Our results show the statistically significant up-regulation of CDC6, CCNE1, MYBL2, ERBB2IP, SON, STK4, CDC27, PRC1, CDC37, TTK and SKIL in the metastatic group when compared to the non-metastatic group.

\section{Validation of selected microRNAs levels in plasma samples as cancer markers}

Three of the most down-regulated miRNAs in the metastatic group, revealed in tumour samples in our microarray analysis (cfa-miR-144, cfa-miR-32 and cfa-miR-374a), and hsa-miR-1246, known for its deregulation in plasma from human breast cancer patients [28], were chosen for the evaluation in plasma samples. Thirty-five out of fifty examined plasma samples were derived from the same dogs which tumours were used for the microarray analysis.

RT-PCR results for these four microRNAs in plasma demonstrated no significant differences in expression level between the metastatic and non-metastatic group. Moreover, plasma levels of these microRNAs did not differ significantly when compared to those in healthy dogs. $P$-values vary from 0.6 in cfa-miR-144, 0.89 in cfa-miR- 


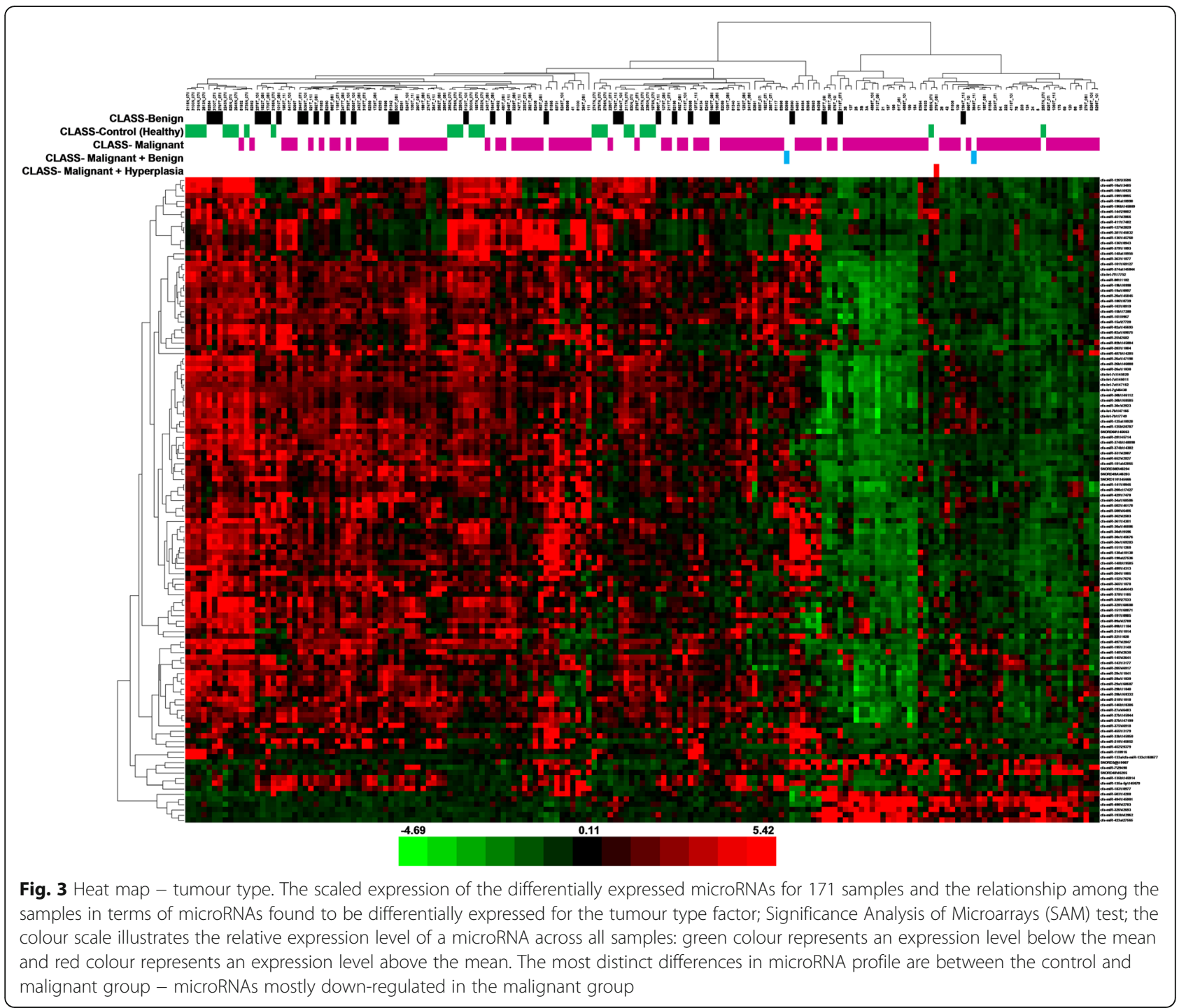

32 , to 0.27 in cfa-miR-374a in contrast to $<1 \mathrm{e}^{-07}$ in tumour samples and fold change 4.74, 3.54 and 3.24, respectively. P-value for hsa-miR-1246 amounts to 0.67 . The results are shown in Fig. 10.

\section{Evaluation of haemolysis risk in plasma samples}

Results of hsa-miR-744-5p and hsa-miR-486-3p expression subtraction revealed that five out of 62 plasma samples show a minor risk of erythrocyte contamination (ranging from 5.01 to 5.7). However, these samples were not excluded from the analysis due to the lack of variation in the levels of investigated microRNAs when compared to the other samples and also occurrence of microRNAs, which are not characteristic for red blood cells.

\section{Discussion}

The results of this study are largely in line with the findings of von Deetzen's group [18]. We also found the significant down-regulation of miR-29b, miR-101, miR143, miR-145 and miR-125a in a metastatic group in comparison with benign tumours. Higher expression of miR-210 in neoplasms than in a control group and upregulation of miR-21 in non-metastasising tumours when compared to normal mammary tissue were similar in the two studies as well. However, there are some discrepancies between our findings and those of von Deetzen's group. For instance, our results show that the expression of miR-203 is down-regulated in benign tumours in comparison with a control group. Von Deetzen et al. found that the expression level of this microRNA is higher in adenoma when compared to normal mammary tissue. Our findings revealed a gradual decrease in miR-10b, miR-125b, miR-136 and let-7f expression levels from normal mammary tissue, through benign tumours and non-metastatic malignant tumours, to metastatic tumours. Von Deetzen's group observed no significant 


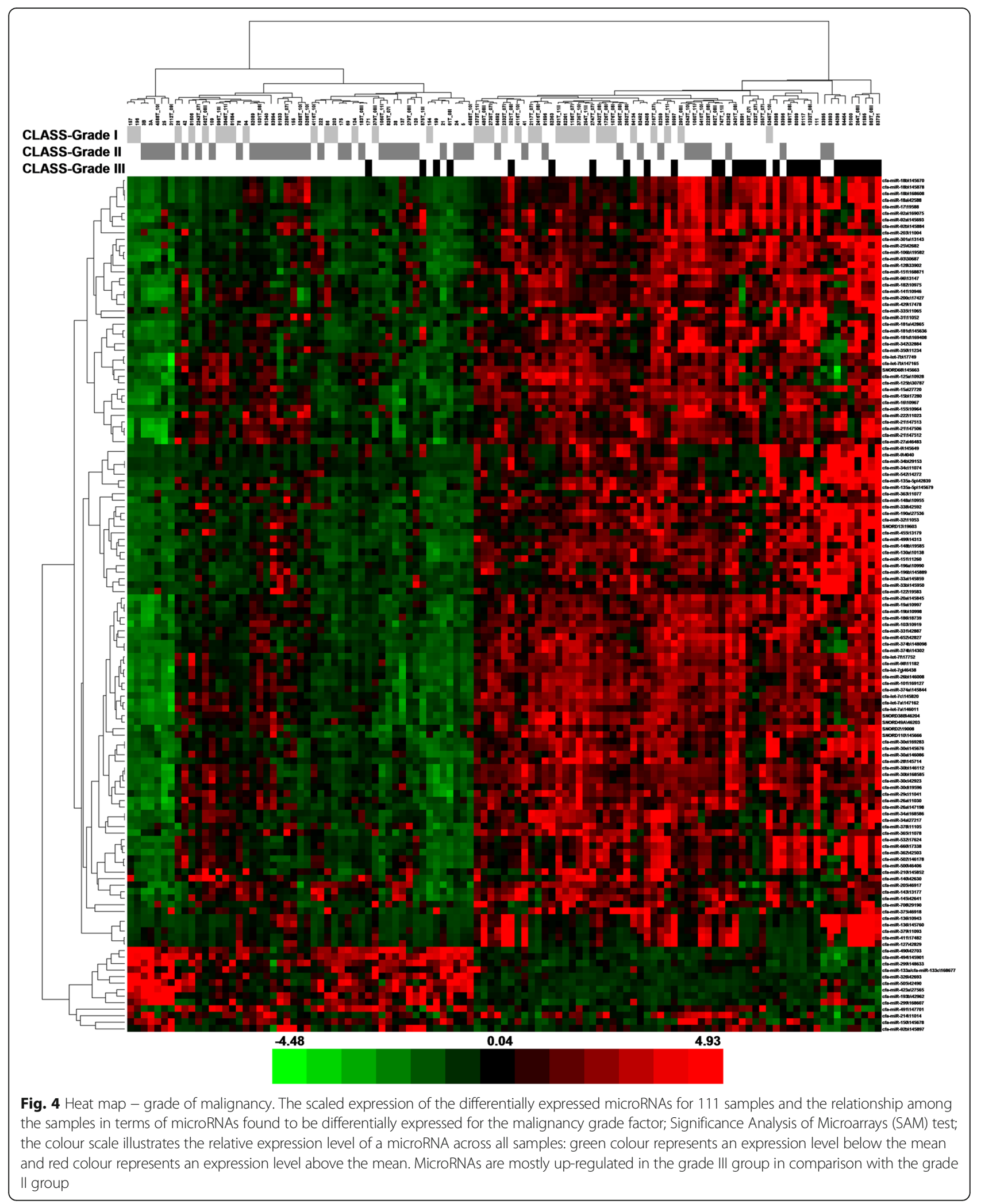




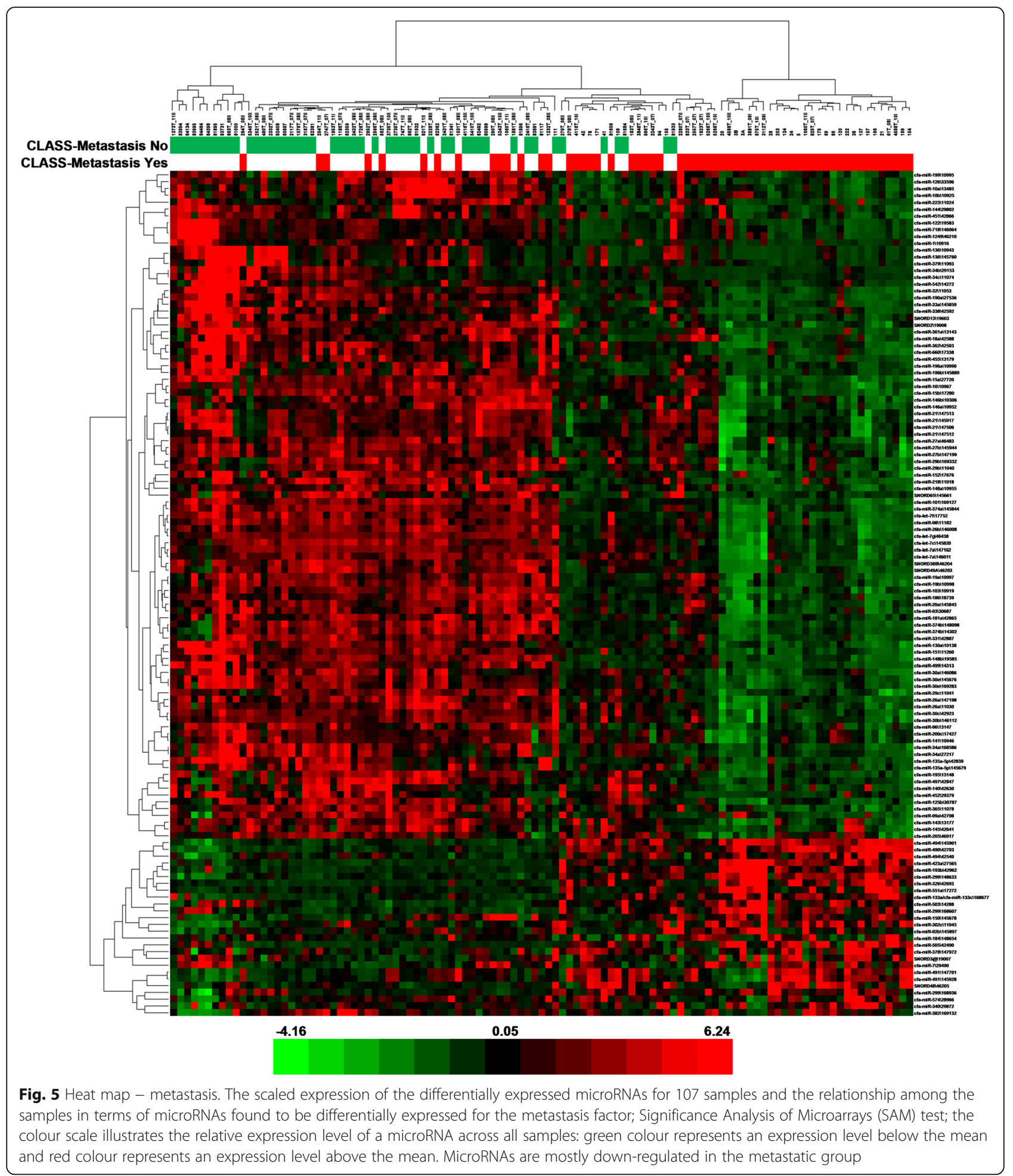

difference in the expression profiles of these microRNA among the examined tissues [18]. The discrepancies between the two studies may be caused by the fact that one microRNA can have many target genes and some tumours with the same histopathological diagnosis can be the result of different derangements of cellular pathways. Among the microRNAs for which the findings of the two groups differ, we found target genes in canine mammary cancer for miR-10b, miR-125b and let-7f (the targets together with their function are included in Additional file 9). The target genes for these microRNAs are engaged in cell cycle regulation, cell differentiation 


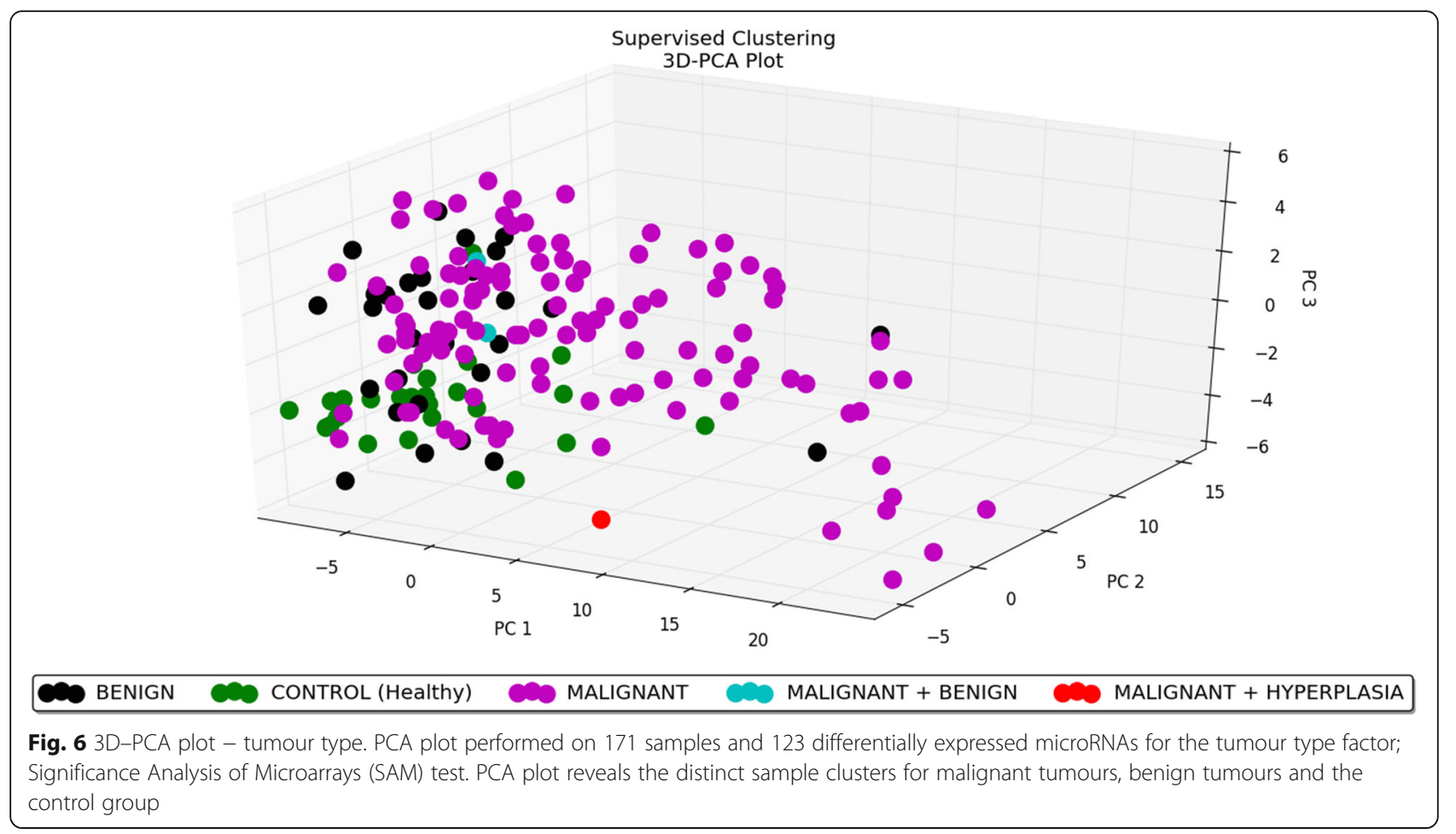

and receptors function. Up-regulation of these genes leads to deregulation of cellular processes and may be a reason for cancer development. However, the discrepancies between the results of this work and the findings of von Deetzen's group may be caused by the differences in the sample types and in the data analysis used in these two studies. Von Deetzen et al. performed their experiments on three types of canine mammary tumours (adenoma, non-metastasising carcinoma and metastasising carcinoma) and analysed all these types separately. We used many histological types of benign, malignant non-metastatic and malignant metastatic tumours and combined together the histological types in the analysis of data.

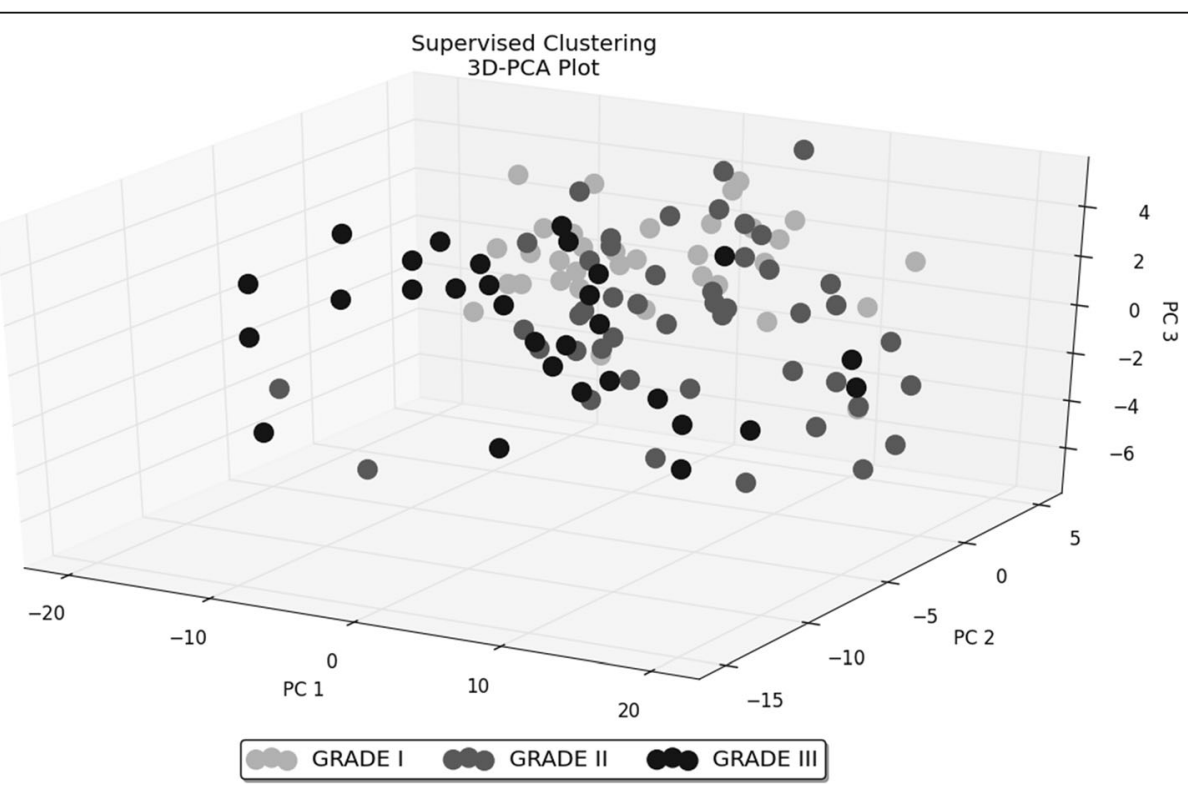

Fig. 7 3D-PCA plot - grade of malignancy. PCA plot performed on 111 samples and 131 differentially expressed microRNAs for the malignancy grade factor; Significance Analysis of Microarrays (SAM) test 


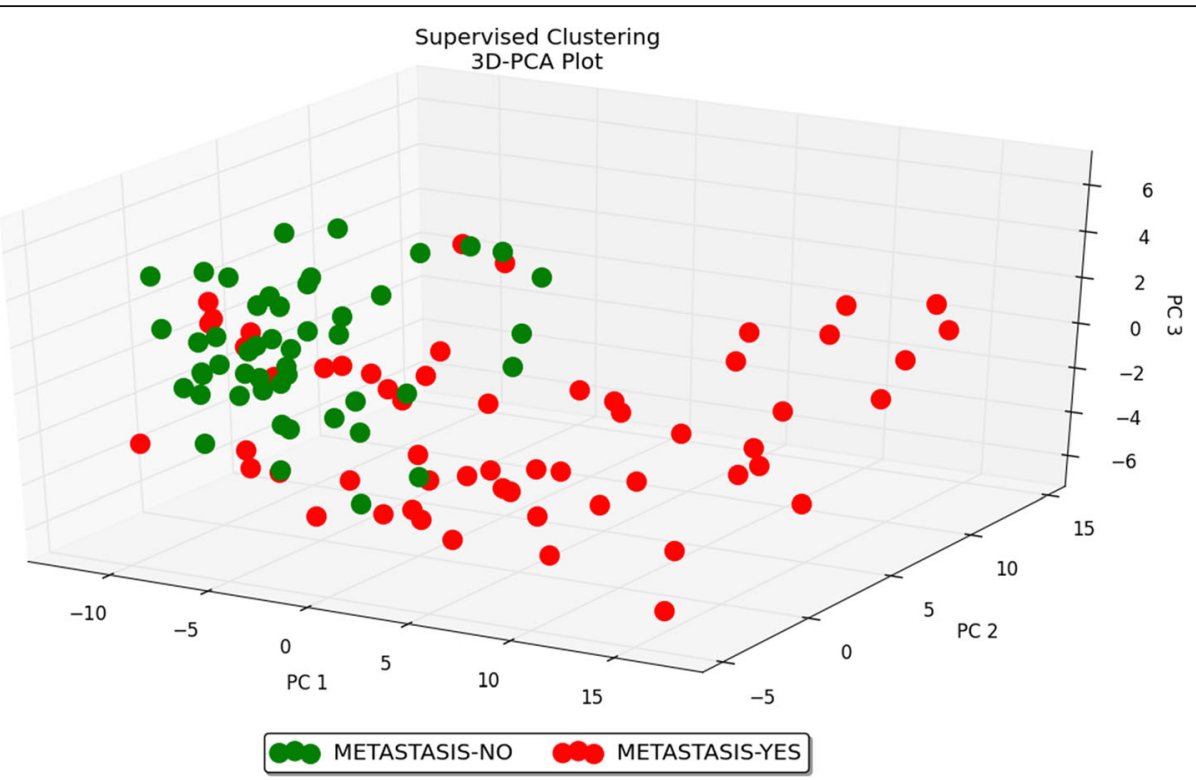

Fig. 8 3D-PCA plot - metastasis. PCA plot performed on 107 samples and 124 differentially expressed microRNAs for the metastasis factor; Significance Analysis of Microarrays (SAM) test. PCA plot reveals the distinct sample clusters for metastatic tumours and non-metastatic tumours

\section{Predicted targets for microRNAs deregulated in} metastatic canine mammary cancer

Klopfleisch et al. compared the global gene expression of metastatic and non-metastatic canine mammary carcinomas. They found 1011 differentially expressed genes, 744 of which were up-regulated and 267 were down-regulated. Among up-regulated genes were those engaged in cell cycle regulation, protein folding, proteasomal degradation and matrix modulation whereas among down-regulated ones where those which play roles in differentiation, growth factor pathways and actin organization [27]. We searched in miRBase [29] for predicted targets of microRNAs that we found differentially expressed in metastatic when compared to non-metastatic canine mammary cancer. Subsequently, we checked if these targets were among the genes deregulated in metastatic mammary cancer (described by Klopfleisch et al. [27]) and whether the expression profiles correlated i.e. under-expression of a microRNA suggests over-expression of its target gene and vice versa. Consequently, we found 44 microRNAs with predicted targets in metastatic canine mammary cancer. Forty-three of these microRNAs are down-regulated whereas one is up-regulated. A list of these 44 microRNAs together with their targets' names and function is included in Additional file 9. Among the targets are mostly genes engaged in cell cycle regulation, cell differentiation and DNA-damage repair, which are all key processes in tumorigenesis.

Table 2 Validation of microarray results in tumour samples

\begin{tabular}{|c|c|c|c|c|c|c|}
\hline \multirow[t]{2}{*}{ microRNA } & \multirow{2}{*}{$\begin{array}{l}\text { microarray } \\
p \text {-value }\end{array}$} & \multirow{2}{*}{$\begin{array}{l}\text { RT-qPCR } \\
p \text {-value }\end{array}$} & \multicolumn{4}{|c|}{ Average RT-qPCR repeats, normalized } \\
\hline & & & Control & Benign & $\begin{array}{l}\text { Malignant } \\
\text { non-metastatic }\end{array}$ & Malignant metastatic \\
\hline let-7c & $<1 \mathrm{e}-07$ & 0.02892256 & 2.066592593 & 1.551592593 & 0.885092593 & 0 \\
\hline miR-26b & $<1 \mathrm{e}-07$ & 0.00001507 & 1.56060648 & 0.04060648 & -0.57989352 & -1.02131944 \\
\hline miR-26a & $<1 \mathrm{e}-07$ & 0.00003571 & 1.11365741 & 0.50621296 & -0.58834259 & -1.03152778 \\
\hline miR-30a & 3.00E-07 & 0.00367713 & -0.09936889 & 0.71563112 & 0.08413112 & -0.70039334 \\
\hline miR-148a & 3.00E-07 & 0.04282469 & 0.32479167 & 0.55945833 & -0.50670833 & -0.37754167 \\
\hline miR-29c & 5.00E-07 & 0.00019157 & 0.79212037 & 0.30412037 & -0.25387963 & -0.84236111 \\
\hline miR-30c & 2.70E-06 & 0.00133947 & 0.2615463 & 0.59621296 & 0.0315463 & -0.88930556 \\
\hline miR-299 & $5.40 \mathrm{E}-06$ & 0.04632324 & 1.899074074 & 0.425074074 & 2.399074074 & 0 \\
\hline miR-10b & $6.00 \mathrm{E}-06$ & 0.01635353 & 0.9961408 & 0.07058524 & -0.46735921 & -0.59936683 \\
\hline miR-30b & $1.74 \mathrm{E}-05$ & 0.00557426 & 0.61328913 & 0.43528913 & -0.40171087 & -0.6468674 \\
\hline
\end{tabular}




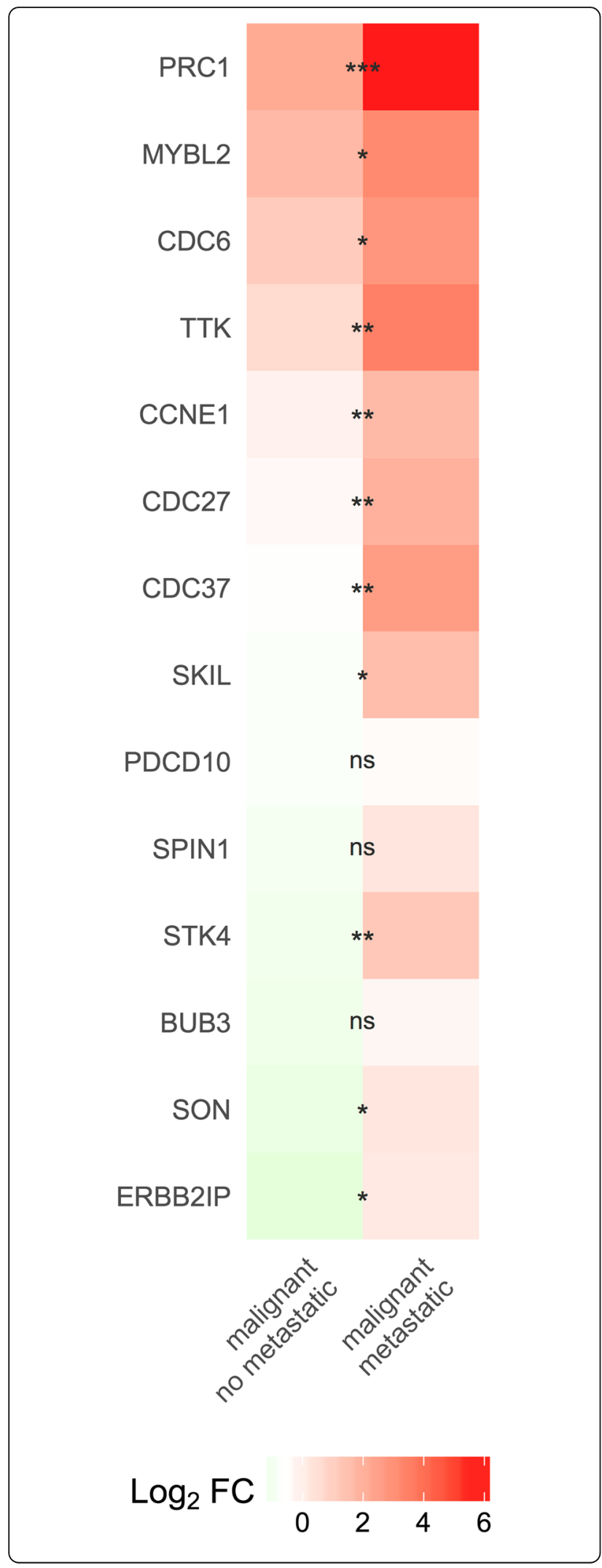

Fig. 9 Heat map - selected targets for microRNAs deregulated in metastatic canine mammary cancer. The scaled expression of CDC6, CCNE1, MYBL2, PDCD10, ERBB2IP, SON, STK4, CDC27, PRC1, CDC37, TTK, SKIL, BUB3 and SPIN1. The analysis performed on ten malignant non-metastatic tumours and ten malignant metastatic tumours. Statistical analysis was made on Ct values normalized with a housekeeping gene; one-way ANOVA followed by Tukey's HSD post hoc tests. Legend: log2 FC - log base 2 from fold change, ${ }^{*}-p$ value $<0.05,{ }^{* *}-p$ value $<0.01,{ }^{* * *}-p$ value $<0.001$

\section{Common microRNAs deregulated in canine mammary cancer and human breast cancer}

Seventeen out of all the microRNAs, which we found deregulated in canine mammary cancer, were also previously described as deregulated in human breast cancer. Twelve of them (miR-10b, miR-15a, miR-19a, miR-26b, miR-30a, miR-30c, miR-125a, miR-125b, miR-148a, miR148b, miR-195 and miR-320) are down-regulated both in dogs and in humans whereas one (miR-494) is upregulated in both species and four (miR-29a, miR-181a, miR-196a and miR-374a) are down-regulated in dogs but up-regulated in humans. Target genes of these 17 microRNAs are mostly engaged in cell cycle regulation, apoptosis and angiogenesis [30-45]. A full list of common microRNAs deregulated in canine mammary cancer and human breast cancer together with the target genes and their function is shown in Table 4.

The discrepancies in the expression levels of miR-29a, miR-181a, miR-196a and miR-374a between dogs and humans may be caused by other target genes having a

Table 3 Validation of selected targets for microRNAs deregulated in metastatic canine mammary cancer

\begin{tabular}{lllll}
\hline Gene & Mean difference & Lower & Upper & $p$-value \\
\hline CDC6 & 1.662166667 & 0.296219571 & 3.028113763 & 0.014739925 \\
CCNE1 & 1.805333334 & 0.698148282 & 2.912518385 & 0.00111525 \\
MYBL2 & 1.469333333 & 0.095498643 & 2.843168024 & 0.034267 \\
PDCD10 & 0.315 & -1.466393723 & 2.096393723 & 0.899858502 \\
ERBB2IP & 1.863333333 & 0.181873946 & 3.544792721 & 0.027609459 \\
SON & 1.691333333 & 0.149694553 & 3.232972114 & 0.029382504 \\
STK4 & 2.356333333 & 0.708656745 & 4.0040099921 & 0.004014445 \\
CDC27 & 2.316333334 & 0.684213855 & 3.948452812 & 0.004297527 \\
PRC1 & 3.368333333 & 1.644772232 & 5.091894434 & 0.000132898 \\
CDC37 & 3.250833333 & 1.273918023 & 5.227748644 & 0.001019454 \\
TTK & 2.8475 & 0.856445769 & 4.838554231 & 0.004013127 \\
SKIL & 2.291666667 & 0.327926258 & 4.255407076 & 0.019726893 \\
BUB3 & 0.976666667 & -0.467839044 & 2.421172377 & 0.232448632 \\
SPIN1 & 1.248333333 & -0.448209573 & 2.944876239 & 0.180817071 \\
\hline The analysis performed on ten malignant non-metastatic tumours and ten \\
malignant metastatic tumours. Statistical analysis was made on Ct values \\
normalized with a housekeeping gene; one-way ANOVA followed by Tukey's \\
HSD post hoc tests & & &
\end{tabular}




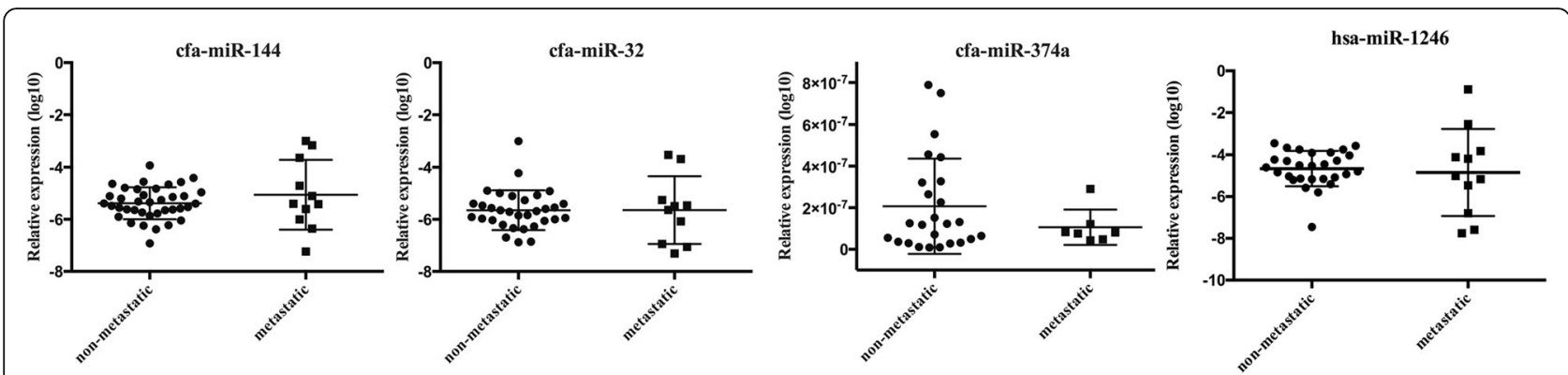

Fig. 10 Expression of selected microRNAs in plasma samples from dogs with non-metastatic and metastatic tumours. Relative expression of cfa-miR-144, cfa-miR-32 cfa-miR-374a and hsa-miR-1246 in plasma samples from dogs with non-metastatic and metastatic tumours. The statistical analysis was performed using Prism version 5.00 software (GraphPad Software, USA). An unpaired, non-parametric Mann-Whitney test was applied. Values are mean \pm SD

stronger influence on canine mammary cancer than human breast cancer development, i.e. other genes than those reported in the literature about breast cancer [34, $40,42,44]$. We found target genes for miR-29a, miR181a and miR-374a in the dogs' mammary cancer. The results are included in Table 5.

Up-regulation of the target genes for these microRNAs leads to a derangement of cell cycle control and cell differentiation and, as a consequence, plays a role in the onset of cancer and, subsequently, in the metastatic progression [27]. However, the differences in the expression profiles of miR-29a, miR-181a, miR-196a and miR-374a may be due to the presence of normal mammary stromal cells in the examined tumour samples, what is sometimes difficult to avoid. Stroma of the normal human mammary gland includes myofibroblasts [46] and that of the dog does not include them [47], so this distinction may be a reason for the microRNA discrepancies between dogs and humans. A role of these microRNAs in myofibroblast differentiation was previously described [48-50].

\section{Validation of selected microRNAs levels in plasma samples as cancer markers}

While deregulated microRNAs in tissue samples regulate known targets involved in tumour development and

Table 4 Common microRNAs deregulated in canine mammary cancer and human breast cancer [30-45]

\begin{tabular}{|c|c|c|c|c|}
\hline microRNA & Canine mammary cancer & Human breast cancer & Target genes & Targets' function \\
\hline miR-10b & down-regulated & down-regulated & BUB1, PLK1, CCNA2 & cell cycle regulation \\
\hline miR-15a & down-regulated & down-regulated & CCNE1 & cell cycle regulation \\
\hline miR-19a & down-regulated & down-regulated & Fra-1 proto-oncogene & $\begin{array}{l}\text { inducing macrophage } \\
\text { polarization }\end{array}$ \\
\hline miR-26b & down-regulated & down-regulated & SLC7A11 & apoptosis \\
\hline miR-29a & down-regulated & up-regulated & Col4a2, Spry1, Timp3 & antiangiogenic \\
\hline miR-30a & down-regulated & down-regulated & MTDH & angiogenesis \\
\hline miR-30c & down-regulated & down-regulated & KRAS & signalling \\
\hline miR-125a & down-regulated & down-regulated & HER2, HER3 & $\begin{array}{l}\text { epidermal growth factor } \\
\text { receptors }\end{array}$ \\
\hline miR-125b & down-regulated & down-regulated & HER2, HER3 & $\begin{array}{l}\text { epidermal growth factor } \\
\text { receptors }\end{array}$ \\
\hline miR-148a & down-regulated & down-regulated & ERBB3 & growth factor \\
\hline miR-148b & down-regulated & down-regulated & ITGA5, ROCK1, PIK3CA, NRAS, CSF1 & \\
\hline miR-181a & down-regulated & up-regulated & ATM & stress-sensor kinase \\
\hline miR-195 & down-regulated & down-regulated & CCNE1 & cyclin \\
\hline miR-196a & down-regulated & up-regulated & ANXA1 & apoptosis \\
\hline miR-320 & down-regulated & down-regulated & TRPC5, NFATC3 & \\
\hline miR-374a & down-regulated & up-regulated & WIF1, PTEN, WNT5A & $\begin{array}{l}\text { negative regulators of the Wnt/ } \\
\beta \text {-catenin signalling cascade }\end{array}$ \\
\hline miR-494 & up-regulated & up-regulated & PTEN & $\begin{array}{l}\text { negative regulator of the Akt/ } \\
\text { PKB signalling pathway }\end{array}$ \\
\hline
\end{tabular}


Table 5 Predicted targets for microRNAs differently deregulated in canine mammary cancer from human breast cancer

\begin{tabular}{|c|c|c|c|c|c|}
\hline microRNA & $\begin{array}{l}\text { Metastatic canine } \\
\text { mammary cancer }\end{array}$ & Target gene & $\begin{array}{l}\text { Metastatic canine } \\
\text { mammary cancer }\end{array}$ & Gene's name & Gene's function \\
\hline cfa-miR-29a & down-regulated & PARD3B & up-regulated & Par-3 family cell polarity regulator beta & cell cycle regulation \\
\hline \multirow[t]{6}{*}{ cfa-miR-181a } & down-regulated & RAD21 & up-regulated & RAD21 homolog (S. pombe) & $\begin{array}{l}\text { cell cycle regulation, } \\
\text { DNA-damage repair, } \\
\text { cell differentiation }\end{array}$ \\
\hline & & BCLAF1 & up-regulated & BCL2-associated transcription factor 1 & cell differentiation \\
\hline & & PRKAA1 & up-regulated & $\begin{array}{l}\text { protein kinase, AMP-activated, alpha } 1 \\
\text { catalytic subunit }\end{array}$ & cell differentiation \\
\hline & & YWHAG & up-regulated & $\begin{array}{l}\text { tyrosine } 3 \text {-monooxygenase/tryptophan } \\
5 \text {-monooxygenase activation protein, } \\
\text { gamma polypeptide }\end{array}$ & cell differentiation \\
\hline & & $\mathrm{ESCO} 2$ & up-regulated & $\begin{array}{l}\text { establishment of sister chromatid cohesion } \\
\mathrm{N} \text {-acetyltransferase } 2\end{array}$ & $\begin{array}{l}\text { cell cycle regulation, } \\
\text { DNA-damage repair }\end{array}$ \\
\hline & & LBR & up-regulated & lamin B receptor & receptor, cell adhesion \\
\hline \multirow[t]{4}{*}{ cfa-miR-374a } & down-regulated & SPIN1 & up-regulated & spindlin 1 & cell cycle regulation \\
\hline & & BUB3 & up-regulated & BUB3 mitotic checkpoint protein & $\begin{array}{l}\text { cell cycle regulation, cell } \\
\text { cycle checkpoint }\end{array}$ \\
\hline & & RAD21 & up-regulated & RAD21 homolog (S. pombe) & $\begin{array}{l}\text { cell differentiation, cell cycle } \\
\text { regulation, DNA-damage repair }\end{array}$ \\
\hline & & SKIN & up-regulated & SKI-like oncogene & cell differentiation \\
\hline
\end{tabular}

metastasis, circulating microRNAs might play a role as stable, specific biomarkers for cancer diagnosis and prognosis [51]. Interestingly, Chen et al. showed that the unique signature of microRNAs in blood samples might follow the same pattern as in tumours [52]. However, this trend has not been observed in our study. The PCR analysis showed no significant differences in the expression of selected miRNAs between the metastatic and non-metastatic group. Such dissimilarity between the obtained results from tumour and plasma samples can be challenging to elucidate, as the mechanism of microRNA release into the blood is not fully understood yet. Steudemann et al. pointed out that microRNAs might be released not only by pathologically changed tissue, but also by other organs in the body modifying its final expression in blood samples [53]. Moreover, a recently discovered role of haemolysis in altering plasma levels of microRNAs put an ongoing question regarding other factors with a similar impact [54].

Many factors may play a role in the analysis of plasma microRNA levels. Due to the variety of conditions and used techniques, the process of raw data normalization might be critical to obtain reliable results. To date, there is no endogenous control for the evaluation of circulating microRNAs. An ideal candidate should remain stable in both healthy and affected individuals and resistant to external factors. Several studies proposed miR-16 as a potential housekeeping gene in human studies. However, the expression of this microRNA was down-regulated in the malignant group in our microarray data and therefore it could not be applicable for the evaluation of plasma samples $[55,56]$. As a result, we used the expression of a synthetic RNA spike-in (UniSp6) for the internal normalization of microRNA level. The average $\mathrm{Ct}$ values within groups were detectable in all the investigated samples, however, did not show any differences between the groups.

\section{Conclusions}

In summary, the microRNA profiling of canine mammary cancer has identified microRNAs that are differentially expressed according to the tumour type, malignancy grade and metastasis factor regardless of the tumours' histological type. The most significant difference in microRNA expression has been found between the metastatic and non-metastatic group. These results are very interesting because, firstly, they suggest that microRNAs regulate mostly the metastasis process (not the malignant transformation) and, secondly, they may constitute molecular markers of metastasis. This is of great predictive importance for the course of a disease because some histopathologically identical malignant tumours have a different clinical outcome. Moreover, due to the microRNA profile similarities between canine mammary cancer and human breast cancer, metastasis biomarkers for dogs can also be further examined as useful for humans.

\section{Additional files}

Additional file 1: Target sequences for validation primer sets - microarray results. (XLSX $43 \mathrm{~kb}$ ) 
Additional file 2: Primers' sequences for selected targets of microRNAs deregulated in canine mammary cancer. (XLSX $46 \mathrm{~kb}$ )

Additional file 3: Characteristics of the plasma samples. Legend: $x$ - the factor does not concern the sample, - - the malignancy grade factor does not concern the sample (for benign tumours), $[$ - samples derived from the same dogs which tumours were used for microarray analysis. (XLS $42 \mathrm{~kb}$ )

Additional file 4: Target sequences for validation primer sets - plasma. (XLSX $41 \mathrm{~kb}$ )

Additional file 5: Characteristics of the tumour samples. Legend: $x-$ the factor does not concern the sample, - - the malignancy grade factor does not concern the sample (for benign tumours), empty spaces - data not available. (XLSX $32 \mathrm{~kb}$ )

Additional file 6: Differentially expressed microRNAs for the tumour type factor. Significance Analysis of Microarrays (SAM) test and one-way ANOVA test. Legend: avg. Hy3 - average array signal intensity of the probes, $\mathrm{d}(\mathrm{i})$ - observed relative difference, (Ctrl) - control, (Benign) - benign tumour, (Mal) - malignant tumour, FDR - false discovery rate. (XLSX 62 kb)

Additional file 7: Differentially expressed microRNAs for the malignancy grade factor. Significance Analysis of Microarrays (SAM) test and one-way ANOVA test. Legend: avg. Hy3 - average array signal intensity of the probes, $d(i)$ - observed relative difference, FDR - false discovery rate. (XLSX 63 kb)

Additional file 8: Differentially expressed microRNAs for the metastasis factor. Significance Analysis of Microarrays (SAM) test and one-way ANOVA test. Legend: avg. Hy3 - average array signal intensity of the probes, d(i) observed relative difference, (No) - non-metastatic tumour, (Yes) - metastatic tumour, FDR - false discovery rate. (XLSX 69 kb)

Additional file 9: Predicted targets for microRNAs deregulated in metastatic canine mammary cancer. (XLSX $21 \mathrm{~kb}$ )

\section{Abbreviations}

FRAs: Fragile sites; HOXD10: homeobox D10; miRNA: microRNA PBS: Phosphate buffered saline; PCA: Principal Component Analysis; RTqPCR: Real-time quantitative PCR; SAM: Significance Analysis of Microarrays; VEGF: Vascular endothelial growth factor; WHO: World Health Organization

\section{Acknowledgements}

MicroRNA array services were performed by Exiqon A/S Company (Denmark) Tumour samples were provided by Eva Hellmén, Robert Klopfleisch, Joanna Mucha, Mariusz Mikow, Slawomir Gizinski and by the following veterinary clinics in Warsaw: Multiwet, Elwet, Kabackie Centrum Weterynarii, Lecznica dla Zwierząt - pl. Hallera 6a, Bolilapka, Bemowo and Arka. Blood samples were provided by the Department of Small Animal Diseases with Clinic (Faculty of Veterinary Medicine, Warsaw University of Life Sciences) and by two veterinary clinics - Multiwet and Elwet.

\section{Funding}

This study was supported by the grant No. 2011/03/B/NZ5/05299 from the National Science Centre (Poland). The authors declare that the funding body has had no role in the design of the study and collection, analysis, and interpretation of data and in writing the manuscript.

\section{Availability of data and materials}

The data generated and analysed during the current study are included in this published article, its supplementary information files and available in the Gene Expression Omnibus (GEO) repository (the accession number: Series GSE103093).

\section{Authors' contributions}

$M B$ and $A R$ performed the literature search. $M B, A R$ and $M K$ prepared the manuscript. MB, AR and BT performed RT-qPCR experiments. KMS and AOG performed statistical analysis of the microarray data. $A R, M B$ and $B T$ performed statistical analysis of RT-qPCR data. MB, AR, MK, KU, KW, JS, JM, MM and SG performed analysis and interpretation of data. RK, EH and ID performed histopathological analysis and classification of the tumours. MK conceived and designed the study. All authors read and approved the final manuscript. All authors agreed to be accountable for all aspects of the work in ensuring that questions related to the accuracy or integrity of any part of the work are appropriately investigated and resolved.

\section{Ethics approval and consent to participate}

Poland: The dogs' owners in Poland gave oral permission for the use of their animals' tissue and blood samples for this work. Tissue sampling in Poland was approved by the III Local Ethical Committee (approval No. 8/2012, 17.01.2012) of the Warsaw University of Life Sciences. Blood samples in Poland were collected according to the Polish legal act concerning experiments performed on animals (Ustawa o doświadczeniach na zwierzętach z dnia 21 stycznia 2005 r. (Dz. U. z 2005 r. Nr 33, poz. 289 z późn.zm.)), no written approval of the study by the Local Ethical Committee was required. Sweden: The dogs' owners in Sweden signed a written agreement for a post-mortem examination of the dogs and sampling of the tumours for scientific purposes. In Sweden, there were no regulations concerning ethical approval of experiments performed on animals at the time of the tumour sampling (1985-1987). Germany: The dogs' owners in Germany gave oral permission for the use of their animals' tissue samples for scientific purposes. Tissue sampling in Germany was performed with the approval of animal welfare authorities of the Veterinary College of the Freie Universitaet Berlin. Surgical excision of tumour biopsies was part of the tumour treatment according to the state of the art treatment and solely to improve the animals' welfare. Furthermore, the animals were under full anaesthesia and not exposed to any additional manipulation due to the inclusion in this study. Therefore, no written approval of the sampling by any ethics committee was required.

\section{Consent for publication}

Not applicable.

\section{Competing interests}

The authors declare that they have no competing interests.

\section{Publisher's Note}

Springer Nature remains neutral with regard to jurisdictional claims in published maps and institutional affiliations.

\section{Author details}

${ }^{1}$ Department of Physiological Sciences, Faculty of Veterinary Medicine, Warsaw University of Life Sciences, Nowoursynowska 159, 02-776 Warsaw, Poland. ${ }^{2}$ Department of Molecular Biology and Genetics, Faculty of Science, SB Building, Bilkent University, 06800 Ankara, Turkey. ${ }^{3}$ Institute of Veterinary Pathology, Freie Universitaet Berlin, Robert-von-Ostertag-Strasse 15, Building 31, 14163 Berlin, Germany. ${ }^{4}$ Department of Anatomy, Physiology and Biochemistry, Swedish University of Agricultural Sciences, Box 7011, 75007 Uppsala, Sweden. ${ }^{5}$ Department of Pathology and Veterinary Diagnostics, Faculty of Veterinary Medicine, Warsaw University of Life Sciences, Nowoursynowska 159, 02-776 Warsaw, Poland. 'Veterinary Clinic 'Elwet', Niepodleglosci 24/30, 02-653 Warsaw, Poland. ${ }^{7}$ Department of Large Animal Diseases with Clinic, Faculty of Veterinary Medicine, Warsaw University of Life Sciences, Nowoursynowska 100, 02-797 Warsaw, Poland.

Received: 10 February 2016 Accepted: 1 November 2017

Published online: 07 November 2017

\section{References}

1. Egenvall A, Bonnett BN, Ohagen $\mathrm{P}$, Olson $\mathrm{P}$, Hedhammar A, von Euler $\mathrm{H}$. Incidence of and survival after mammary tumors in a population of over 80,000 insured female dogs in Sweden from 1995 to 2002. Prev Vet Med. 2005;69:109-27.

2. Misdorp W. In: Meuten DJ, editor. Tumors of the mammary gland. 4th ed. Ames: lowa State Press; 2002. p. 575-606.

3. Shafiee R, Javanbakht J, Atyabi N, Kheradmand P, Kheradmand D, Bahrami A, et al. Diagnosis, classification and grading of canine mammary tumours as a model to study human breast cancer: an Clinico-Cytohistopathological study with environmental factors influencing public health and medicine. Cancer Cell Int. 2013;13:79.

4. Weigelt B, Horlings HM, Kreike B, Hayes MM, Hauptmann M, Wessels LF, et al. Refinement of breast cancer classification by molecular characterization of histological special types. J Pathol. 2008;216:141-50.

5. Gilbertson SR, Kurzman ID, Zachrau RE, Hurvitz Al, Black MM. Canine mammary epithelial neoplasms: biologic implications of morphologic characteristics assessed in 232 dogs. Vet Pathol. 1983;20:127-42. 
6. Hellmen E, Svensson S. Progression of canine mammary tumours as reflected by DNA ploidy in primary tumours and their metastases. J Comp Pathol. 1995;113:327-42.

7. Rosol TJ, Tannehill-Gregg SH, LeRoy BE, Mandl S, Contag CH. Animal models of bone metastasis. Cancer. 2003;97(Suppl 3):748-57.

8. Al-Kahiry W, Omer HH, Saeed NM, Hamid GA. Late presentation of breast cancer in Aden, Yemen. Gulf J Oncolog. 2011;9:7-11.

9. Boggs RM, Wright ZM, Stickney MJ, Porter WW, Murphy KE. MicroRNA expression in canine mammary cancer. Mamm Genome. 2008;19:561-9.

10. Uva P, Aurisicchio L, Watters J, Loboda A, Kulkarni A, Castle J, et al. Comparative expression pathway analysis of human and canine mammary tumors. BMC Genomics. 2009;10:135.

11. Krol M, Motyl T. Exploiting cancer genomics in pet animals to gain advantage for personalized medicine decisions. J Appl Genet. 2014;55:337-41.

12. Iorio MV, Ferracin M, Liu CG, Veronese A, Spizzo R, Sabbioni S, et al. MicroRNA gene expression deregulation in human breast cancer. Cancer Res. 2005;65:7065-70.

13. Calin GA, Sevignani C, Dumitru CD, Hyslop T, Noch E, Yendamuri S, et al. Human microRNA genes are frequently located at fragile sites and genomic regions involved in cancers. Proc Natl Acad Sci U S A. 2004;101:2999-3004.

14. Chang TC, Wentzel EA, Kent OA, Ramachandran K, Mullendore M, Lee KH, et al. Transactivation of miR-34a by p53 broadly influences gene expression and promotes apoptosis. Mol Cell. 2007;26:745-52.

15. Scott GK, Mattie MD, Berger CE, Benz SC, Benz CC. Rapid alteration of microRNA levels by histone deacetylase inhibition. Cancer Res. 2006;66:1277-81.

16. Mertens-Talcott SU, Chintharlapalli S, Li X, Safe S. The oncogenic microRNA27a targets genes that regulate specificity protein transcription factors and the G2-M checkpoint in MDA-MB-231 breast cancer cells. Cancer Res. 2007:67:11001-11.

17. Ma L, Teruya-Feldstein J, Weinberg RA. Tumour invasion and metastasis initiated by microRNA-10b in breast cancer. Nature. 2007;449:682-8.

18. von Deetzen MC, Schmeck BT, Gruber AD, Klopfleisch R. Malignancy associated microRNA expression changes in canine mammary cancer of different malignancies. ISRN Vet Sci. 2014; https://doi.org/10.1155/2014/148597.

19. Hellmen E, Bergstrom R, Holmberg L, Spangberg IB, Hansson K, Lindgren A. Prognostic factors in canine mammary tumors: a multivariate study of 202 consecutive cases. Vet Pathol. 1993;30:20-7.

20. Misdorp W, Else RW, Hellmen E, Lipscomb TP. Histologic classification of mammary tumor of the dog and the cat in: WHO international histological classification tumor of domestic animals. Washington, DC. 1999;7:3-29.

21. Elston CW, Ellis IO. Assessment of histological grade. In: Elston CW, Ellis IO, editors. Systemic pathology: the breast, vol. 13. 3rd ed. Edinburgh: ChurchillLivingstone; 1998. p. 365-84.

22. Rossum Gv. Python tutorial. Technical Report CS-R9526. Centrum voor Wiskunde en Informatica (CWI), Amsterdam. 1995.

23. Hunter JD. Matplotlib: a 2D graphics environment. Comput Sci Eng. 2007;9:90-5.

24. Blondal T, Jensby Nielsen S, Baker A, Andreasen D, Mouritzen P, Wrang Teilum M, et al. Assessing sample and miRNA profile quality in serum and plasma or other biofluids. Methods. 2013:59:S1-6.

25. Kirschner MB, Edelman JJ, Kao SC, Vallely MP, van Zandwijk N, Reid G. The impact of Hemolysis on cell-free microRNA biomarkers. Front Genet. 2013;4:94

26. Schmittgen TD, Livak KJ. Analyzing real-time PCR data by the comparative CT method. Nat Protoc. 2008:3:1101-8.

27. Klopfleisch R, Lenze D, Hummel M, Gruber AD. Metastatic canine mammary carcinomas can be identified by a gene expression profile that partly overlaps with human breast cancer profiles. BMC Cancer. 2010;10:618.

28. Fu L, Li Z, Zhu J, Wang P, Fan G, Dai $Y$, et al. Serum expression levels of microRNA-382-3p, $-598-3 p,-1246$ and -184 in breast cancer patients. Oncol Lett. 2016;12:269-74.

29. Kozomara A, Griffiths-Jones S. miRBase: integrating microRNA annotation and deep-sequencing data. Nucleic Acids Res. 2011;39:D152-7.

30. Biagioni F, Bossel Ben-Moshe N, Fontemaggi G, Canu V, Mori F, Antoniani B, et al. miR-10b*, a master inhibitor of the cell cycle, is down-regulated in human breast tumours. EMBO Mol Med. 2012;4:1214-29.

31. Luo Q, Li X, Li J, Kong X, Zhang J, Chen L, et al. MiR-15a is underexpressed and inhibits the cell cycle by targeting CCNE1 in breast cancer. Int J Oncol. 2013:43:1212-8

32. Yang J, Zhang Z, Chen C, Liu Y, Si Q, Chuang TH, et al. MicroRNA-19a-3p inhibits breast cancer progression and metastasis by inducing macrophage polarization through downregulated expression of Fra-1 proto-oncogene. Oncogene. 2014;33:3014-23.
33. Liu XX, Li XJ, Zhang B, Liang YJ, Zhou CX, Cao DX, et al. MicroRNA-26b is underexpressed in human breast cancer and induces cell apoptosis by targeting SLC7A11. FEBS Lett. 2011;585:1363-7.

34. Mathsyaraja H, Thies K, Taffany DA, Deighan C, Liu T, Yu L, et al. CSF1-ETS2induced microRNA in myeloid cells promote metastatic tumor growth. Oncogene. 2015;34:3651-61

35. Zhang N, Wang X, Huo Q, Sun M, Cai C, Liu Z, et al. MicroRNA-30a suppresses breast tumor growth and metastasis by targeting metadherin. Oncogene. 2014;33:3119-28

36. Tanic M, Yanowsky K, Rodriguez-Antona C, Andres R, Marquez-Rodas I, Osorio A, et al. Deregulated miRNAs in hereditary breast cancer revealed a role for miR-30c in regulating KRAS oncogene. PLoS One. 2012;7:e38847.

37. O'Day E, Lal A. MicroRNAs and their target gene networks in breast cancer. Breast Cancer Res. 2010;12:201.

38. Yu J, Li Q, Xu Q, Liu L, Jiang B. MiR-148a inhibits angiogenesis by targeting ERBB3. J Biomed Res. 2011;25:170-7.

39. Cimino D, De Pitta C, Orso F, Zampini M, Casara S, Penna E, et al. miR148b is a major coordinator of breast cancer progression in a relapse-associated microRNA signature by targeting ITGA5, ROCK1, PIK3CA, NRAS, and CSF1. FASEB J. 2013;27:1223-35.

40. Bisso A, Faleschini M, Zampa F, Capaci V, De Santa J, Santarpia L, et al. Oncogenic miR-181a/b affect the DNA damage response in aggressive breast cancer. Cell Cycle. 2013;12:1679-87.

41. Luo Q, Wei C, Li X, Li J, Chen L, Huang Y, et al. MicroRNA-195-5p is a potential diagnostic and therapeutic target for breast cancer. Oncol Rep. 2014:31:1096-102

42. Luthra R, Singh RR, Luthra MG, Li YX, Hannah C, Romans AM, et al. MicroRNA-196a targets annexin A1: a microRNA-mediated mechanism of annexin A1 downregulation in cancers. Oncogene. 2008;27(52):6667-78.

43. He DX, XT G, Jiang L, Jin J, Ma XA. Methylation-based regulatory network for microRNA 320a in chemoresistant breast cancer. Mol Pharmacol. 2014;86:536-47.

44. Cai J, Guan H, Fang L, Yang Y, Zhu X, Yuan J, et al. MicroRNA-374a activates Wnt/beta-catenin signaling to promote breast cancer metastasis. J Clin Invest. 2013:123:566-79.

45. Liu Y, Lai L, Chen Q, Song Y, Xu S, Ma F, et al. MicroRNA-494 is required for the accumulation and functions of tumor-expanded myeloid-derived suppressor cells via targeting of PTEN. J Immunol. 2012;188:5500-10.

46. Polyak K, Kalluri R. The role of the microenvironment in mammary gland development and cancer. Cold Spring Harb Perspect Biol. 2010;2:a003244.

47. Yoshimura H, Michishita M, Ohkusu-Tsukada K, Takahashi K. Increased presence of stromal myofibroblasts and tenascin- $\mathrm{C}$ with malignant progression in canine mammary tumors. Vet Pathol. 2011;48:313-21.

48. Lancon A, Michaille JJ, Latruffe N. Effects of dietary phytophenols on the expression of microRNAs involved in mammalian cell homeostasis. J Sci Food Agric. 2013:93:3155-64.

49. Dong N, Tang X, Xu B. miRNA-181a inhibits the proliferation, migration, and epithelial-mesenchymal transition of lens epithelial cells. Invest Ophthalmol Vis Sci. 2015:56:993-1001.

50. Wang L, Zhou L, Jiang P, Lu L, Chen X, Lan H, et al. Loss of miR-29 in myoblasts contributes to dystrophic muscle pathogenesis. Mol Ther. 2012;20:1222-33.

51. Brase JC, Wuttig D, Kuner R, Sultmann H. Serum microRNAs as non-invasive biomarkers for cancer. Mol Cancer. 2010;9:306.

52. Chen J, Yao D, Li Y, Chen H, He C, Ding N, et al. Serum microRNA expression levels can predict lymph node metastasis in patients with earlystage cervical squamous cell carcinoma. Int J Mol Med. 2013;32:557-67.

53. Steudemann C, Bauersachs S, Weber K, Wess G. Detection and comparison of microRNA expression in the serum of Doberman pinschers with dilated cardiomyopathy and healthy controls. BMC Vet Res. 2013;9:12.

54. Kirschner MB, Kao SC, Edelman JJ, Armstrong NJ, Vallely MP, van Zandwijk $\mathrm{N}$, et al. Haemolysis during sample preparation alters microRNA content of plasma. PLoS One. 2011;6:e24145.

55. Heneghan HM, Miller N, Lowery AJ, Sweeney KJ, Newell J, Kerin MJ. Circulating microRNAs as novel minimally invasive biomarkers for breast cancer. Ann Surg. 2010:251:499-505.

56. Huang Z, Huang D, Ni S, Peng Z, Sheng W, Plasma DX. microRNAs are promising novel biomarkers for early detection of colorectal cancer. Int J Cancer. 2010;127:118-26. 